\title{
NEW APPROACH IN MODIFYING QUENCHING PROCESSES BASED ON POSSIBILITY OF CONTROLLING STEEL'S SURFACE TEMPERATURE BY INSULATING LAYER
}

\author{
Nikolai Kobasko \\ Intensive Technologies Ltd \\ 68/1 Peremohy ave., Kyiv, Ukraine 03113 \\ nkobasko@gmail.com
}

\begin{abstract}
In the paper is shown a possibility to govern surface temperature of steel parts during quenching by controlling the thickness of the insulating layer. That results in developing the new quenching technologies like austempering process via cold liquids. The investigations were performed with a low concentration of the polyoxyethylene in cold water using $20 \mathrm{~mm}$ cylindrical probe instrumented with two thermocouples. It is established that with the increase concentration of polyoxyethylene in cold water (beginning from $0.001 \%$ ) different heat transfer modes are observed resulting in the elimination of film boiling process at $0.001 \%$ concentration, increasing surface temperature of probe during self - regulated thermal process, periodical changing of heat flux densities, slow cooling of surface temperature like in oil when concentration reaches $1 \%$ polyoxyethylene in water, and so on. It is underlined that low concentration of polyoxyethylene in water can serve as an excellent quenchant for accelerated and uniform cooling of steel parts decreasing by this way the cost of a coolant. In this case accelerated cooling should be interrupted at proper time to provide optimal hardened layer afterr quenching. Such approach guarantees increasing service life of steel parts after accelerated cooling with the significant decrease of their cost and eliminates carburization process, The technology can be used for hardening large steel parts like large wind mill gears, large bearing rings, etc.
\end{abstract}

Keywords: polyoxyethylene, low concentration, insulating layer, governing surface temperature, new technology, increased surface life.

\section{Introduction}

Authors of the publications [1-4] considered surface insulating layers and came to conclusion that $1 \%$ concentration of inverse solubility polyalkylene glycol (PAG) polymer eliminates completely film boiling process due to creation of the thin insulating polymeric layer on the surface of steel parts. This paper presents the results of investigations which show that extremely low concentration of polyoxyethylene in water $(0.001 \%)$ provides the same effect as PAG does and concentration $1 \%$ of polyoxyethylene in water decreases cooling rate which is comparable with the oil quenching. Along with decreasing core cooling rate, low concentration of polymers in water can increase surface temperature of steel parts during self-regulated thermal process up to $400-450{ }^{\circ} \mathrm{C}$ [4]. This fact is very important in terms of performing austempering processes via cold liquids [4]. The polyoxyethylene chemical composition is $[5,6]$ :

$$
\left[-\mathrm{OCH}_{2} \mathrm{CH}_{2}-\right]_{\mathrm{n}} \text {. }
$$

Number $\mathrm{n}$ is responsible for molecule weight of polyoxyethylene [5]. As known [5, 6], very small amount of polyoxyethylene in water $(0.001-0.003 \%)$ decreases hydrodynamic resistance by $70 \%$. It is expected that the same amount of polyoxyethylene (POE) in water will affect its cooling intensity too, eliminating film boiling process. Intensive and uniform cooling increases significantly service life of hardened machine components and tools.

In [5] it is indicated that POE dissolves perfectly in cold water, however above $100{ }^{\circ} \mathrm{C}$ it acts as polymer of inverse solubility creating insulating layers on the surface of quenched steel parts. As known, insulating layer decreases initial heat flux density which can be calculated using equation (2) [1]:

$$
\mathrm{q}=\frac{\mathrm{q}_{0}}{\left(1+2 \frac{\delta}{\mathrm{R}} \frac{\lambda}{\lambda_{\text {coat }}}\right)}
$$


Here $\mathrm{q}$ is heat flux density in $\mathrm{W} / \mathrm{m}^{2} ; \mathrm{q}_{0}$ is initial heat flux density in $\mathrm{W} / \mathrm{m}^{2} ; \delta$ is thickness of insulating layer in $\mathrm{m} ; \mathrm{R}$ is radius in $\mathrm{m} ; \lambda$ is thermal conductivity of steel in $\mathrm{W} / \mathrm{mK} ; \lambda_{\text {coat }}$ is thermal conductivity of coating (surface layer) in $\mathrm{W} / \mathrm{mK}$.

Author of [7] showed that insulating polymeric layer forms immediately after immersion of the cylindrical probe into water polymer solution of inverse solubility (Fig. 1).

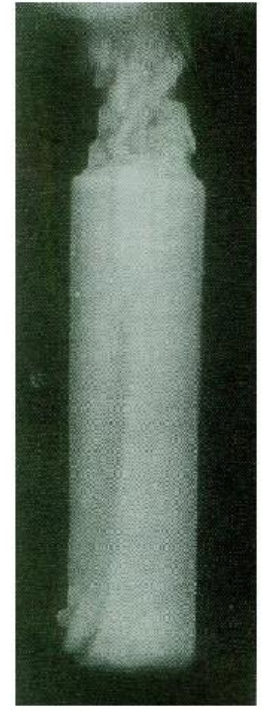

$a$



$b$

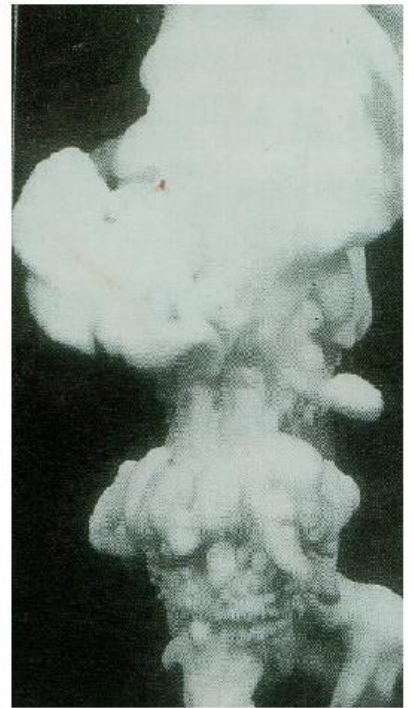

Fig. 1. Immediate formation of insulating layer during cooling cylindrical silver probe $15 \mathrm{~mm}$ in diameter and $45 \mathrm{~mm}$ long in water solution of inverse solubility polymer at $25^{\circ} \mathrm{C}$ [7]:

$$
a-6 \mathrm{sec} ; b-6.35 \mathrm{sec} ; c-7.65 \mathrm{sec}[7]
$$

\section{Method of testing polyoxyethylene water solutions and results of experiments}

Water solutions of polyoxyethylene of small concentration were tested using cylindrical probe $20 \mathrm{~mm}$ in diameter and $80 \mathrm{~mm}$ long made of stainless steel AISI 304. To make ideal contact junction of thermocouple with a steel probe a special instrumentation was used as described in the literature $[8,9]$. First, junction of the core thermocouple was welded and then fixed thoroughly by a pin [9]. Surface thermocouples were welded and then thoroughly polished using the French method [8]. In spite of these accurate preparations and checking ideal welding of surface thermocouples, the strange "shoulders" on surface cooling curves and oscillation of surface temperature were constantly observed which in many cases were quite different. The results of experiments were fulfilled in 1984 and were not published since in that time nobody could explain such strange behavior of surface temperature. Authors [4] who observed similar effect during quenching in water solutions of polymers explained such strange behavior of surface temperature by varying thickness of the polymeric insulating layer which is clearly seen on the Fig. 1 [7]. Let's consider more attentively results of accurate testing of low concentration of polyoxyethylene in water. The experiments (Fig. 2-8), as mentioned above, were fulfilled in 1984 using probe of $20 \mathrm{~mm}$ in diameter. Concentration of polyoxyethylene in water was $0.001 \%, 0.01 \%, 0.1 \%, 0.2 \%, 0.3 \%$, and $1 \%$. When quenching instrumented with two thermocouples probe in water $0.001 \%$ solution, there was no film boiling at all (Fig. 2).

As seen from Fig. 2, when quenching cylindrical probe in low concentration of POE in water $(0.001 \%)$, cooling curves are similar to cooling curves obtained during quenching probes in water salt solutions of optimal concentration. Probably, low concentration of POE in water increases the first critical heat flux density which exceeds the initial heat flux density that is why there is no film boiling at all. There is no enough POE in water to create an insulating surface layer. In this case boiling process is governed by Eq. (3), creating a shoulder during transient nucleate boiling process which maintains at the level of $100{ }^{\circ} \mathrm{C}$. 


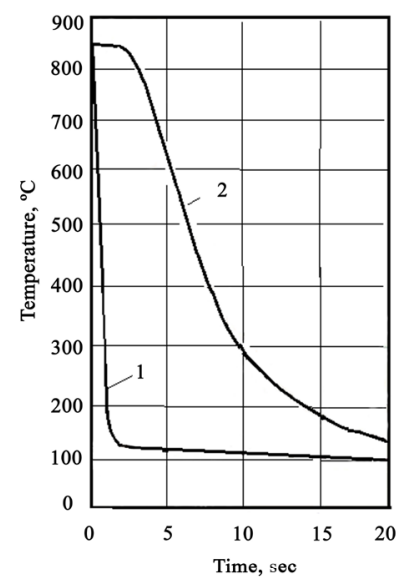

Fig. 2. Cooling curves versus time during quenching cylindrical probe $20 \mathrm{~mm}$ diameter and $80 \mathrm{~mm}$ long in water solution of polyoxyethylene $(0.001 \%)$ at $23{ }^{\circ} \mathrm{C}$ : 1 is surface temperature; 2 is core temperature

The cooling time of the transient nucleate boiling process is calculated using Eq. (3) $[1,4,9]$.

$$
\tau_{\mathrm{nb}}=\Omega \mathrm{k}_{\mathrm{F}} \frac{\mathrm{D}^{2}}{\mathrm{a}} .
$$

Here $\tau_{\mathrm{nb}}$ is time of nucleate boiling process in sec; the value of $\Omega$ is a function of the convective Biot number Bi; D is thickness in $\mathrm{m}$; a is thermal diffusivity of steel $\mathrm{in}^{2} / \mathrm{s}$. As an example, $\Omega$ values for convective Biot numbers are provided in [9]. Note that $\Omega \rightarrow 0$ when $\mathrm{Bi} \rightarrow \infty$.

Further increase of POE in water (up to $0.01 \%$ ) indicates creation of the shoulder at a temperature $425^{\circ} \mathrm{C}$ (Fig. 3) that coincides well with the investigations of the authors $[4,10]$.

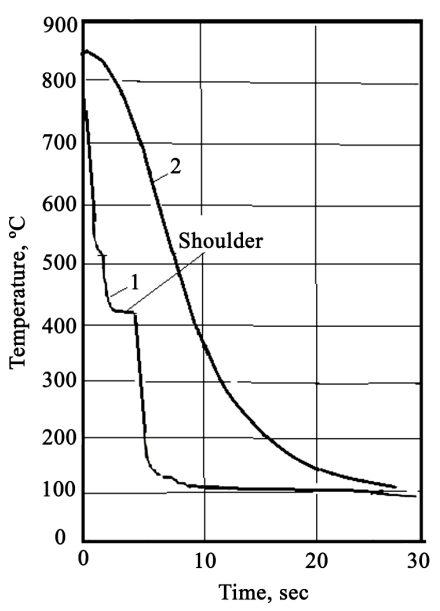

Fig. 3. Cooling curves versus time during quenching cylindrical probe $20 \mathrm{~mm}$ diameter and $80 \mathrm{~mm}$ long in water solution of polyoxyethylene (0.01\%) at 23: 1 is surface temperature; 2 is core temperature

However, at concentration $0.1 \%$ of POE in water shoulder is observed at $175^{\circ} \mathrm{C}$ (Fig. 4).

It means that surface insulating layer is not stable and can vary as shown in Fig. 1 [7]. Similar behavior of surface temperature described in publications $[4,10]$ is shown in Fig. 5. Shoulder in this case is at the level of $430^{\circ} \mathrm{C}$.

The explanation for increasing surface temperature during self-regulated thermal process caused by existing polymeric insulating layer can be taken from Eq. (4) [4]: 
or

$$
\frac{\operatorname{grad}_{\mathrm{in}}}{\operatorname{grad}_{\mathrm{sl}}}=\frac{\lambda_{\mathrm{sl}}}{\lambda_{\mathrm{in}}}
$$

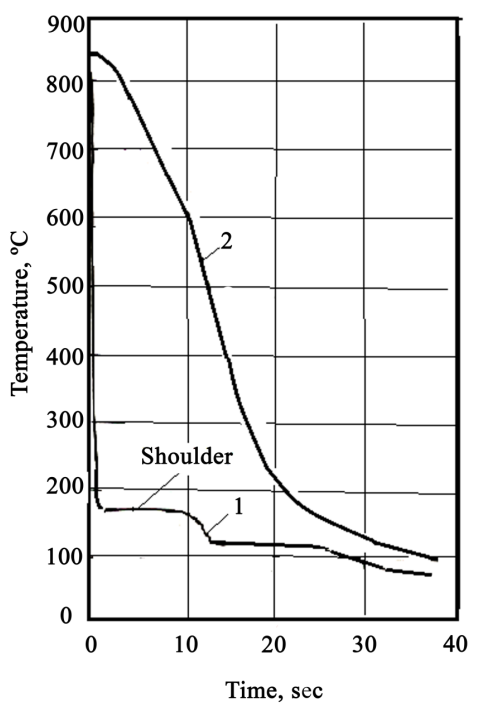

Fig. 4. Cooling curves versus time during quenching cylindrical probe $20 \mathrm{~mm}$ diameter and $80 \mathrm{~mm}$ long in water solution of polyoxyethylene $(0.1 \%)$ at $23{ }^{\circ} \mathrm{C}: 1$ is surface temperature; 2 is core temperature

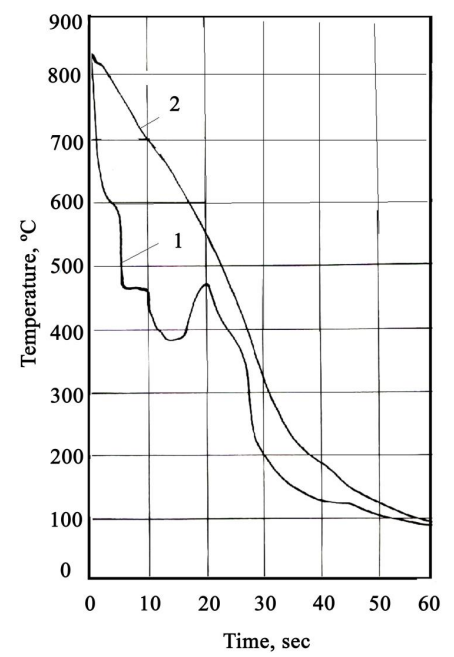

Fig. 5. Cooling curves versus time during quenching of cylindrical probe $20 \mathrm{~mm}$ in diameter and $80 \mathrm{~mm}$ long in water solution of polyoxyethylene $(0.2 \%)$ at $23{ }^{\circ} \mathrm{C}: 1$ is surface temperature; 2 is core temperature

Here $\lambda_{\text {in }}$ is thermal conductivity of the insulating layer; $\lambda_{\mathrm{sl}}$ is thermal conductivity of steel; $\operatorname{grad}_{\text {in }}$ is temperature gradient in the insulating layer; $\operatorname{grad}_{\mathrm{sl}}$ is temperature gradient in steel probe.

Since surface temperature on the insulating layer during self-regulated thermal process maintains at the level of boiling point of a liquid, surface temperature of steel part or probe must arise to more elevated value in order to satisfy ratio (5). As known, thermal conductivity of insulating polymeric layer is very low and is equal approximately to $0.2 \mathrm{~W} / \mathrm{mK}$ when at the same time the thermal conductivity of steel in average is $22 \mathrm{~W} / \mathrm{mK}$ [1]. Thus, temperature gradient in the insulating layer is 
several times larger as compared with temperature gradient in steel part or probe. Such temperature gradients are possible if surface temperature of probe or steel part increases and maintains at the elevated temperature relatively a long time [4].

Fig. 6, 7 show periodical changing of surface temperature and heat flux densities. It takes place when concentration of POE in cold water is $0.3 \%$. There is a simple explanation for periodical behavior of heat flux densities. Thermal resistance at $0.3 \%$ POE in water is big enough to allow dropping of surface temperature below $100{ }^{\circ} \mathrm{C}$ where insulating layer is dissolved back into cold water. Since at that moment no insulating layer at all, surface heat flux density increases reaching the first critical heat flux density where film boiling starts again creating new insulating layer. Such process is repeated several times until inner heat flux density satisfies convection mode. Using experimental data shown in Fig. 6, authors [11, 12] investigated behavior of heat flux densities by solving inverse problem (Fig. 7). As seen from Fig. 7, the heat flux density at the beginning oscillates between $5 \mathrm{MW} / \mathrm{m}^{2}$ and $15 \mathrm{MW} / \mathrm{m}^{2}$ and at the end oscillates between $3 \mathrm{MW} / \mathrm{m}^{2}$ and $13.5 \mathrm{MW} / \mathrm{m}^{2}$. Note that a ratio qmin/qmax at the beginning is equal to 0.33 and at the end is equal to 0.22 . In numerous published books and papers [13-18] the ratio $\frac{\mathrm{q}_{\mathrm{cr} 2}}{\mathrm{q}_{\mathrm{cr} 1}}$ is equal to 0.2 . From the provided consideration, one can come to conclusion that maximal heat flux densities in Fig. 7 do not differ significantly from the first critical heat flux density qcrl. If so, it means that small amount of POE $(0.3 \%)$ in water increases the first critical heat flux density up to $15 \mathrm{MW} / \mathrm{m}^{2}$ Such high data are observed during quenching of steel parts in water alkali solution of optimal concentration. This information is extremely important for optimizing cooling processes taking place in small concentration of water polymer solutions.

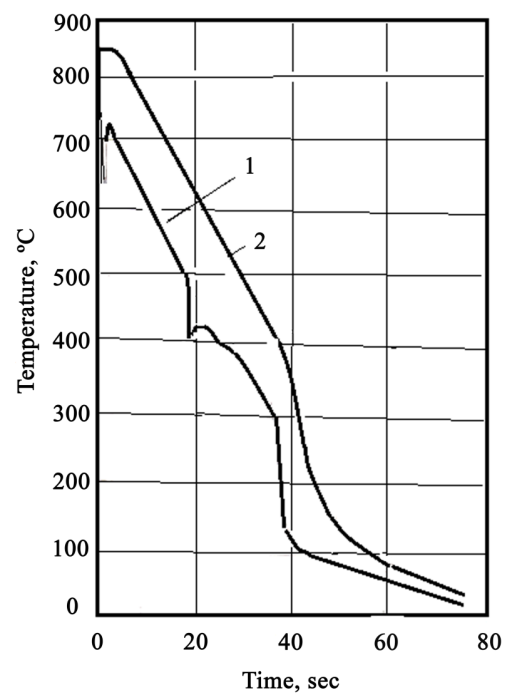

Fig. 6. Cooling curves versus time during quenching cylindrical probe $20 \mathrm{~mm}$ diameter and $80 \mathrm{~mm}$ long in water solution of polyoxyethylene $(0.3 \%)$ at $20^{\circ} \mathrm{C}: 1$ is surface temperature; 2 is core temperature

When quenching cylindrical probe in $1 \%$ water solution of polyoxyethylene, cooling curves match the cooling curves which are observed during quenching in oil (Fig. 8).

It looks like insulating layer is stable and repeatable. The polyoxyethylene is not expensive polymer which is available everywhere. It can serve during manufacturing of quenchants for accelerated and uniform cooling which is achieved due to absence of film boiling processes. Low concentration of $\mathrm{POE}$ in water can be used also for performing austempering processes via cold liquids, and improving IQ - 3 technology due to decreasing almost two times hydrodynamics resistance during pumping of a coolant [19]. However, such quenchants can perfectly work in heat treating industry if they are the package which includes software for proper interruption of accelerated cooling, quenchant and technological process are controlled constantly, and exact chemical composition of hardened steel part is known. It should be also noted that existing methods of controlling cooling 
intensity of quenchants based on use of standard Inconel 600 probes [20-22] with one thermocouple instrumented at the core of the probe are not suitable for controlling austempering processes via cold liquids. The same is true for an idea to restore surface temperature using core cooling curve of a probe. Experiments provided in this paper clearly showed that it is impossible to restore surface temperature of a probe using core cooling curves (Fig. 3-7). That is why development of correct methods for testing and controlling cooling intensity of quenchants is very important for the practice.

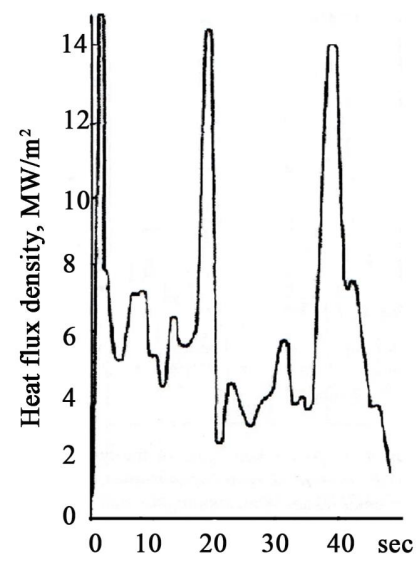

Fig. 7. Periodic changes of heat flux density versus time during quenching of a cylindrical probe made of AISI 304 steel in $0.3 \%$ water solution of polyoxyethylene at $20^{\circ} \mathrm{C}$ (probe diameter $20 \mathrm{~mm}$, length $80 \mathrm{~mm}$, initial temperature $850^{\circ} \mathrm{C}$ ). Periodic changes are explained by multiple transitions from film boiling to nucleate boiling [12]

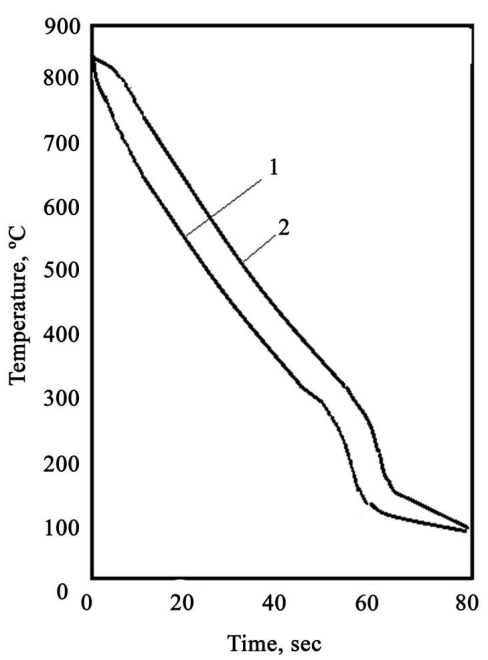

Fig. 8. Cooling curves versus time during quenching cylindrical probe $20 \mathrm{~mm}$ diameter and $80 \mathrm{~mm}$ long in water solution of polyoxyethylene $(1 \%)$ at $20^{\circ} \mathrm{C}: 1$ is surface temperature; 2 is core temperature

\section{Simplified method for cooling time interruption}

A proposal for the use of a universal correlation to calculate the heating and cooling time that would be applicable to any steel is based on earlier work reported by the author described in Ref. [23] and is now considerably extended.

Cooling time of any form of steel part is calculated using Eq. (6) $[9,19]$ and existing computer program available from Intensive Technologies Ltd, Kyiv, Ukraine [24, 25]:

$$
\frac{\mathrm{aKn}}{\mathrm{K}} \tau=\left(\frac{\mathrm{k}_{\mathrm{i}} \mathrm{Bi}_{\mathrm{V}}}{2.095+3.873 \mathrm{Bi}_{\mathrm{V}}}+\ln \theta_{0}\right) \text {. }
$$


Here $\tau$ is cooling time in seconds; $\mathrm{Bi}_{\mathrm{v}}$ is generalized Biot number; $\mathrm{K}$ is Kondrat'ev form factor; a is thermal diffusivity of a material $\mathrm{m}^{2} / \mathrm{s}$; $\mathrm{Kn}$ is Kondrat'ev dimensionless number; $\theta_{0}$ is dimensionless temperature.

\section{Optimal hardenability steels suitable for quenching in low concentration of POE water solutions}

In water solutions of low concentration of polymers optimal hardenability steels can be successfully quenched [26]. Recently issued, a new patent on alloy LH steel (UA Patent No 114174, 2017) solves this problem making possibility use it for large steel components on the basis of developed method of its composing. Optimal hardenability steels which provides optimal hardened martensitic surface layer with maximal compression residual stresses in it and bainitic or pearlitic microstructure at the core after intensive quenching can be achieved using established by author [26] the similarity ratio (7):

$$
\begin{gathered}
\frac{\mathrm{DI}_{\mathrm{a}}}{\mathrm{D}_{\text {opt }}}=0.35 \pm 0.095 . \\
\mathrm{DI}_{\mathrm{a}}=\mathrm{f}(\mathrm{DI}, \text { Form,Kn }) .
\end{gathered}
$$

Here $\mathrm{DI}_{\mathrm{a}}$ is a critical size of steel part; $\mathrm{D}_{\text {opt }}$ is an actual size of steel component in $\mathrm{m}$; $\mathrm{Kn}$ is Kondrat'ev dimensionless number.

Equation (7) differs significantly from the patented method of chemical composition discussed early in [26]. It contains Kn number which allows correction chemical composition of steel to be suitable for condition of cooling in the interval of $0.2<\mathrm{Kn}<0.8$.

According to Grossmann [27], critical diameter DI for cylinder depends on chemical composition of steel, Eq. (7), and it can be calculated as

$$
\mathrm{DI}=25.4 \times \mathrm{f}_{\mathrm{Fe}} \times \mathrm{f}_{\mathrm{Mn}} \times \mathrm{f}_{\mathrm{Si}} \times \mathrm{f}_{\mathrm{Cr}} \times \mathrm{f}_{\mathrm{Ni}} \times \ldots .
$$

Hardenability factors $f_{F e}$ and $f_{x}$ are provided in [28]. For cylindrical forms $D I=D I$ For more complicated forms of steel parts the function (7) should be used which is calculated by computer program. This program can also find suitable chemical composition among already existing steel grades to fit any form and size of a product.

\section{Discussion}

The paper discusses the role of insulating surface layer on behavior of surface temperature of steel parts during their quenching. Many investigators [28-35] were dealing with studying phenomena taking place on the surface of steel parts with and without partly insulation. As known, alloy and high alloy steels are quenched slowly in oils to prevent crack formation and reduce distortion during hardening. To make environment cleaner by eliminating smoke, oils are substitute by water solution of polymers $10 \%, 20 \%, 30 \%$ which show the same cooling curve as oil do. Since cooling rate in oils is slow, metallurgists add more alloy elements to steel to increase its hardenability and provide proper hardening. In this paper author proposes using low concentration the polyoxyethylene polymer in water (0.001-0.2\%) for hardening alloy steels. Mechanism of elimination film boiling during quenching and reducing almost two times hydrodynamics resistance, when low concentration (0.001-0.2\%) of the polyoxyethylene polymer is dissolved in water (0.001-0.2 \%), should be, of course, further carefully investigated.

The low concentration of polymers in water can be used for hardening optimal hardenability steels to reduce cardinally alloy elements in steel and provide optimal hardened surface layer resulting in formation the surface compression residual stresses. Both low concentration polymers in water and low amount of alloy elements in steel, reduces cost of hardened steel parts. Moreover, costly powerful propellers to agitate vigorously water polymer solutions will be not more in use because hydrodynamics emitters will compete with them [26]. A package (low concentration polymers in 
water, reduced amount of alloy elements in steel, software for governing hardening process and cheap hydrodynamics emitters) is a way for global introduce new technology which is 2-3 times less costly as compared with conventional technologies. This new technology occupies so called stay away zone where will be no more risk in crack formation when smart quenching is provided [19]. The new technology can be used for hardening large steel parts like mill wind gears and large bearing rings to eliminate long lasting carburizing processes.

More useful information on accelerated and uniform interrupted cooling of steel parts in water flow and water solution of polymers one can find in the published papers. [34, 35].

\section{Conclusions}

1. If further investigated, the low concentration of polyoxyethylene $(0.001-0.003 \%)$ in cold water, along with decreasing hydrodynamic resistance by $70 \%$, can be used as a quenchant for accelerated and uniform cooling of steel parts and its concentration $0.1-0.2 \%$ can be used for performing austempering processes via cold liquids.

2. To guarantee absence of quench crack formation during accelerated cooling of steel parts in low concentration of polyoxyethylene in cold water, accelerated cooling should be interrupted at proper time. For this purpose a simplified method of calculation and software are available from the Intensive Technologies Ltd, Kyiv, Ukraine [24, 25].

3. To create high surface compression residual stresses in steel parts during quenching in low concentration of polyoxyethylene water solutions, chemical composition of steel should be governed by modified optimizing criterion taking into account Kondrat'ev number Kn responsible for cooling intensity of a quenchant.

4. A significant progress can be made globally in reducing the cost of heat treating processes if low concentration of polymers as a quenchant and appropriate software for governing cooling processes will be applied into practice as a package.

\section{References}

[1] Kobasko, N. (2017). Cooling intensity of inverse solubility polyalkylene glykol polymers and some results of investigations focused on minimizing distortion of metal components. EUREKA: Physics and Engineering, 2, 55-62. doi: https://doi.org/10.21303/2461-4262.2017.00294

[2] Kobasko, N. I. (2012). Real and Effective Heat Transfer Coefficients (HTCs) Used for Computer Simulation of Transient Nucleate Boiling Processes during Quenching. Materials Performance and Characterization, 1 (1), 104656. doi: https://doi.org/10.1520/mpc104656

[3] Kovalenko, G. V., Kobasko, N. I., Khalatov, A. A., (1987). A Method of Hardening of Steel Components. USSR, Certificate No. 1355634. Bul. No. 44.

[4] Kobasko, N., Liscic, B. (2017). Liscic/Petrofer probe to investigate real industrial hardening processes and some fundamentals during quenching of steel parts in liquid media. EUREKA: Physics and Engineering, 6, 48-56. doi: https://doi.org/10.21303/2461-4262.2017.00495

[5] Polietilenoksid. Available at: https://mplast.by/encyklopedia/polietilenoksid/

[6] Balley, F. E., Koleske, J. V. (1976). Poly (Ethylene Oxyde). Elsevier, 184. doi: https://doi.org/10.1016/ b978-0-12-073250-0.x5001-6

[7] Tensi, H. M. (1992). Wetting Kinematics. Theory and Technology of Quenching, 93-116. doi: https://doi.org/10.1007/978-3-662-01596-4_5

[8] French, H. J. (1930). The Quenching of Steels. Cleveland, Ohio, USA: American Society for Steel Treating, 177.

[9] Kobasko, N. I. (1980). Steel Quenching in Liquid Media Under Pressure. Kyiv: Naukova Dumka, 206.

[10] Liščić, B. (2016). Measurement and Recording of Quenching Intensity in Workshop Conditions Based on Temperature Gradients. Materials Performance and Characterization, 5 (1), MPC20160007. doi: https://doi.org/10.1520/mpc20160007

[11] Krivoshei, F. A. (1993). Solution of Inverse Problems of Heat Transfer Based on the Method of Statistical Regularization. Kyiv. 
[12] Kobasko, N. I., Krivoshei, F. A. (1994). On the Mechanism of Temperature and Heat Flow Oscillations in Cooling Metallic Specimens in Aqueous Solutions of Polymers. Dokl. Akad. Nauk Ukr., 11, 90-94.

[13] Tolubinsky, V. I. (1980). Teploobmen pri kipenii [Heat transfer at boiling]. Kyiv: Naukova Dumka.

[14] Kutateladze, S. S. (1963). Fundamentals of Heat Transfer. New York: Academic Press, 485.

[15] Kutateladze, S. S. (1950). Hydrodynamic Crisis Model of Heat Transfer in Boiling Liquid at Free Convection. Journal of Engineering Physics, 20 (11), 1389-1392.

[16] Incropera, F. P., DeWitt, D. P. (1981). Fundamentals of Heat and Mass Transfer. New York: John Wiley \& Sons.

[17] Isachenko, V. P., Osipova, V. A., Sukomel, A. S. (1981). Teploperedacha [Heat transfer]. Moscow: Energomash.

[18] Liscic, B. (2003). Critical Heat-Flux Densities, Quenching Intensity and Heat Extraction Dynamics During Quenching in Vaporizable Liquids. Proceedings of the 4th International Conference on Quenching and the Control of Distortion. Beijing, 21-28.

[19] Kobasko, N., Aronov, M., Powell, J., Totten, G. (2010). Intensive Quenching Systems: Engineering and Design. ASTM International, 242. doi: https://oi.org/10.1520/mnl64-eb

[20] ASTM Standard D6200-97: Standard Test Method for Determination of Cooling Characteristics of Quench Oils by Cooling Curve Analysis (2001). Annual Book of ASTM Standards, ASTM International, West Conshohocken, PA.

[21] ASTM Standard D6482-99: Standard Test Method for Determination of Cooling Characteristics of Aqueous Polymer Quenchants with Agitation (Tensi Method) (2000). Annual Book of ASTM Standards, ASTM International, West Conshohocken, PA.

[22] ASTM Standard D6549-00: Standard Test Method for Determination of Cooling Characteristics of Quenchants by Cooling Curve Analysis with Agitation (Drayton Unit) (2000). Annual Book of ASTM Standards, ASTM International, West Conshohocken, PA.

[23] Kobasko, N. I. (2017). A Universal Correlation for the Calculation of Heating and Cooling Time of Any Steel. Materials Performance and Characterization, 6 (1), 20170034. doi: https://doi.org/10.1520/ mpc20170034

[24] Austempering Calculation Software. Available at: http://www.itl.kiev.ua/en/software/ austempering

[25] Optimized Polymer Quenching Calculation Software. Available at: http://www.itl.kiev.ua/en/software/optimized-polymer-calc

[26] Kobasko, N. I. (2018). Optimal Hardenability Steel and Method for Its Composing. Lambert Academic Publishing, 122.

[27] Grossmann, M. A. (1964). Principles of Heat Treatment. Ohio: American Society for Metals, 302.

[28] Dossett, J. I., Totten, G. E. (Eds.) (2013). ASM Handbook, Volume 4A: Steel Heat Treating Fundamentals and Processes. ASM International, 784.

[29] Narazaki, M., Fuchizawa, S., Kogawara, M., Inaba, M. (1993). Effects of Surface Oxidation on Cooling Characteristics during Quenching of Heated Metals in Subcooled Water. Tetsu-to-Hagane, 79 (5), 583589. doi: https://doi.org/10.2355/tetsutohagane1955.79.5_583

[30] Frenkel, Ya. I. (1959). Kinetic Theory of Liquids, Selected Works. Vol. 3. Moscow.

[31] Fedorov, V. I., Kovalenko, G. V., Kostanchuk, D. M. (1977). Boiling of fluid on a metal surface. Journal of Engineering Physics, 32 (1), 10-14. doi: https://doi.org/10.1007/bf00860120

[32] Moreaux, F., Beck, G. (1992). Effect of Workpiece Surface Properties on Cooling Behaviour. Theory and Technology of Quenching, 182-207. doi: https://doi.org/10.1007/978-3-662-01596-4_7

[33] Walker, J. (1988). Boiling and the Leidenfrost Effect, Fundamentals of Physics. John Willey \& Sons.

[34] Daming, M. (1990). Intense Quenching Method for Preventing Quench Cracking. Proceedings of the Seventh International Congress on Heat Treatment and Technology of Surface Coating. Vol. 2. Moscow, 62-71.

[35] Han, S. W., Kang, S. H., Totten, G. E., Webster, G. M. (1995). Immersion Time Quenching. Advanced Materials \& Processes, 148 (3), 42AA-42DD. 